\section{The future of general practice in South Africa}

There is a shortage of human resources in Africa but also poor management by governments with poor working environments and career paths in primary care ${ }^{1}$ and maldistribution of healthcare professionals. Post-apartheid South Africa saw black nurses moved out of hospitals dominated by white doctors to 'nurse-driven' district health services, citing 'doctor shortage'. The government has struggled to regulate the private sector that exploded as public hospitals deteriorated and specialists moved in droves to private hospitals. Total healthcare expenditure for South Africa in 2012-2013 was R122 billion for public services for 42 million people, with a private sector spend of R103 billion on only 8.7 million people.

The African National Congress has been championing national health insurance (NHI) since 2008, including GPs as providers. Government has included primary healthcare $(\mathrm{PHC})$ re-engineering in $\mathrm{NHI}$ policy since 2011, fashioned around three streams: district specialist teams, school health teams and $\mathrm{PHC}$ outreach teams, consisting of two professional nurses, one enrolled nurse, and six community health workers, providing all $\mathrm{PHC}$ services, including treatment for "minor illness', to a defined population of 7660 people. ${ }^{2}$ Interim evaluation suggests that this model is struggling with accountability and skills.

The role of the GP has been declining in both private and public sectors. Doctors are not attracted to public sector primary care in clinics where they are meaninglessly pushing numbers' as employees and subordinate to nurse managers. ${ }^{3}$ Patients bypass clinics to get to doctors in hospitals or visit private GPs. GPs, as doctors just finishing their medical school and setting up shop with no postgraduate training, occupy a threatened space with ageing (mean age 46 years) and declining competencies.

GPs are willing to engage with government capitation at the same cost as the public services PHC. ${ }^{4}$ This could be linked to postgraduate training in family medicine and will move many more clinicians into primary care. Government has ample resources, including grants from the European Union and UK, but is reluctant to contract fully with GPs, even in pilots, with the Minister of Health responding, "How will we monitor them?'. Instead the minister wants to contract doctors to work in public clinics for a few hours a week. Lessons from the UK, to include and incentivise GPs as complete service providers, appear lost. There is a strong need for better primary care in South Africa. Resources are not the real problem, but political will and trust are.

\section{Shabir Moosa,}

Family Physician and Senior Clinical Lecturer in the Department of Family Medicine, Johannesburg Health District and Faculty of Health Sciences, University of Witwatersrand, Johannesburg, South Africa. E-mail: shabiradrmoosa.co.za

\section{REFERENCES}

1. Moosa S, Wojczewski S, Hoffman K, et al. Why there is an inverse primary-care law in Africa. Lancet Global Health 2013; 1(6): e332-e333.

2. Department of Health Republic of South Africa. National Health Insurance in South Africa. Pretoria: Department of Health Republic of South Africa. 2011.

3. Moosa S, Gibbs A. A focus group study of primary health care in Johannesburg Health District, South Africa: 'We are just pushing numbers'. S Afr Fam Pract 2014: in press

4. Moosa S, Luiz J, Carmichael T. Introducing a national health insurance system in South Africa: A general practitioner's bottom-up approach to costing. S Afr Med J2012: 102(10): 794-797.

DOI: 10.3399/bjgp14X676997

\section{Suicide risk among farming patients and the effects of HS2}

Bridget Osborne's editorial ${ }^{1}$ describing the increased risk of suicide among farmers overlooks the effects of HS2 on the mental health of the rural community. The proposal for HS2 marches on despite an enormous amount of doubt from all quarters. Furthermore the technical report from Temple-ERM ${ }^{2}$ regarding the health impact has been superficial to say the least, hidden quietly as Appendix 9 of the HS2 Sustainability Statement and with only 29 references. For example there is no mention in HS2 health assessment policy of the suicide risk of farmers, apparently well known to the government through their Suicide Prevention Policy. ${ }^{3}$ Surprisingly, according to the health analysis there is no legislative requirement for health impact assessments with these major projects, something which should sound alarm bells in the corridors of medical and public health colleges and the Department of Health.

HS2 will take up to 20 years to complete. ${ }^{4}$ The effects of 20 years of emotional, economic and financial uncertainty will lead to mental health issues for many communities. There is anecdotal evidence that rural businesses that supply farmers have already seen a $20 \%$ drop in turnover (B Osborne, personal communication, 2013) reflecting farmers insecurities about their business future.

Furthermore farmers have little reassurance in a fickle and as yet unclear compensation scheme to counteract their hardship. The government has already stated the project has a limited budget and should represent 'best value' for the public rather than supporting farmers and rural communities to the degree of the true financial loss. This merely provides further justification for farmers worries that they will be last in line for any handouts, after consultant and construction costs.

I fear for the mental health of hard working farmers as a result of the economic suffocation HS2 planning is producing on farmers and rural communities, the hidden blight of the 'pre-construction threat' never mentioned in any press release or government statement so far. Osborne refers to the 'ups and downs' of farming. It is likely to be down for a long time in certain parts of central England and the mental health effects will be on the whole of the rural community not just farmers. Public Health should ensure all major projects have a more robust, deeply evidenced and searching analysis of health outcomes.

Alwyn Ralphs,

GP Partner, Wolstanton Medical Centre,

Newcastle-under-Lyme.

E-mail: alwyn.ralphslabtinternet.com

\section{REFERENCES}

1. Osborne B. Why our farming patients are at an increased risk of taking their own lives this year. $\mathrm{Br} \mathrm{J}$ Gen Pract 2013; 63: 624

2. Temple-ERM. High Speed Rail: Consultation on the 